\title{
TRADUÇÃO/TRANSLATION
}

\section{O OUTRO NIETZSCHE: JUSTIÇA CONTRA UTOPIA MORAL ${ }^{1}$}

\author{
Reinhart MAURER ${ }^{2}$ \\ Tradução: Oswaldo GIACÓIA JÚNIOR ${ }^{3}$
}

1 Pensa-se, com esse título, que exista um Nietzsche diverso daquele habitualmente admitido até então, particularmente diverso de como o apresentam interpretações tendencialmente fascistas, marxistas, liberalistas e até anarquistas, pós-estrutural-ultrapluralistas (ou seja, francesas mais recentes). Pensa-se, sobretudo, um Nietzsche tal que nem pode ser reivindicado pela "direita" em sentido político corrente, nem censurado pela "esquerda", quiçá do lado marxista, com a censura de que seja em muitos aspectos um autor pré-fascista, mas que haja nele também outros lados aceitáveis. É nesse sentido que Ernst Bloch fala do outro Nietzsche, e com isso pensa num que ocasionalmente apreendesse o futuro do homem à luz de seu "Princípio Esperança". 4

O outro Nietzsche, que eu penso, é aquele que se encontra atrás da fachada cheia de efeitos, até ambiciosa de efeitos e que primeiro salta aos olhos em sua filosofia; atrás das fortes e impregnantes palavras, teses e vaticínios. E gostaria até de afirmar que esse outro é o autêntico Nietzsche, e que só o intérprete que não fica preso às palavras fortes avança para a camada de sustentação da filosofia de

\footnotetext{
1 Uma primeira versão deste texto, muito mutilada, foi publicada em: Deutsche Zeitschrift fuer Philosophie, v.38, p.1019-1026, 1990, sob o título: O Outro Nietzsche. Para a Crítica da Utopia Moral. O texto ora presente é uma reelaboração e ampliação da versão original. Um prosseguimento dessa interpretação de Nietzsche foi recentemente publicado: Teses sobre Nietzsche como Teólogo e Crítico Fundamental. In: Nietzsche-Studien, v.23, p.102-22, 1994. Na nota n.1 daquela versão de 1990, publicada logo em seguida ao colapso da República Democrática da Alemanha, lê-se, ademais: "Não nos deixemos enganar: a situação geral se tornou insegura. Por isso Nietzsche surge agora no proscênio como o filósofo da insegurança" - um julgamento correto da situação, conforme se mostrou desde então.

2 Instituto de Filosofia e Ciências I - Universidade Livre de Berlim (RFA) - Berlim - Alemanha.

3 Departamento de Filosofia - IFCH - Unicamp - 13081-970 - Campinas - SP - Brasil.

4 E. Bloch: Herança deste tempo, edição ampliada, Frankfurt a. M., 1962, p.358 s. In: O impulso Nietzsche, do mesmo: O princípio esperança, Frankfurt a. M. 1959.
} 
Nietzsche. Nietzsche fala com freqüência de máscaras: seu estilo poderoso em efeitos é a máscara primária, atrás da qual ele se oculta.

2 Considerado superficialmente, Nietzsche é, em muitas passagens, cru, radical, ocasionalmente um "macho" marcialmente imponente. Isso, porém, é uma fachada ou máscara de proteção, atrás da qual ele oculta sua sensibilidade, fragilidade, vulnerabilidade. A essa idiossincrasia pessoal corresponde um traço fundamental de sua filosofia. Sua autocompreensão a esse respeito não necessita ser verdadeira; dever-se-ia, entretanto, tomar conhecimento e manter à vista que ela remete a um antagonismo em sua filosofia, análogo àquele de sua personalidade. De acordo com isso, sua radicalidade crítica tem um sentido compensatório. Nietzsche vê uma monstruosa unilateralidade no desenvolvimento da humanidade na direção de uma decadência igualitária, pretensamente humanitária, e gostaria de equilibrá-la por meio da ênfase no contrapólo aristocrático reprimido. A provocativa agudeza de seu protesto se esclarece com base em seu diagnóstico de uma crescente prepotência e presunçosa autocerteza da linha geral da moderna visão de mundo (Weltanschauung), que se tem pela única humana.

O alvo do pensar compensatório de Nietzsche se denomina, em conjunto, justiça, como reconhecimento de uma pluralidade não necessariamente caótica, mas disposta em hierarquia. Em nome dela, Nietzsche sustenta resistência contra monopolizações ou absolutizações em nome da verdade, da moral, ou também da própria nação, e toma partido por aquilo que desse modo é reprimido. Ele pensa manifestamente também em si mesmo, quando escreve: “... naturezas compensatórias que, entre franceses ou americanos, substituem em si o ódio aos alemães, entre alemães o ódio aos judeus, por uma benevolência proposital - não por contradição, mas por necessidade de justiça. Dispostos dessa maneira contra períodos históricos inteiros" (Nietzsche, 1980, v.9, p.419). ${ }^{5}$

O que significa disposto contra períodos inteiros do desenvolvimento da moral, possivelmente durando mais de 2 mil anos, pode-se depreender de Para a Genealogia da Moral. É interessante que ele também já tenha visto que agora há que se tomar partido compensatoriamente pelas coisas, que sucumbem a um uso abusivo (Vemutzung) pretensamente humanitário: "Amor e justiça para com as coisas seja vossa escola"..

Isso é escrito manifestamente contra uma humanística, isto é, antropologicamente limitada filantropia e justiça, e com isso contra uma vontade de poder coletiva que se coloca de modo absoluto perante a natureza coisificada. Diante da agora emergente crise ecológica, começamos a suspeitar que essa monopolização poderia nos ter saído muito mal. Filantropia sem amor pelas coisas com as quais nos mantemos

\footnotetext{
5 Daqui por diante abreviada como KSA.

6 KSA. 10, p. 255.
} 

ruinoso a mais longo prazo.

3 Um pensar compensatório segundo sua própria autocompreensão, que critica como unilateralidade com falsa pretensão à totalidade tudo aquilo que é avaliado como bom, belo e verdadeiro pela linha geral humanístico-progressiva, tem que parecer, precisamente a essa linha geral, como despropositado, mau ou louco. ${ }^{7}$ Pois ela se considera, com efeito, o único caminho certo para o futuro da humanidade.

Quando abrangemos com a vista contra quem Nietzsche declara suas pretensões compensatórias, isto é, contra todo o programa científico-moral-político de desenvolvimento do novo tempo (Neuzeit), então se mede a grandeza do desafio que ele apresenta. Seu ataque se dirige, por princípio, contra todas as linhas gerais, pretensões à totalidade, ideologias de felicitação da humanidade, em particular, porém, contra a linha geral de nossa história de proveniência (Herkunftsgeschichte) judaico-cristã e seu moderno prolongamento, aparentemente não mais dependente de Deus, em democracia, socialismo, anarquismo. Ele se dirige contra a pretensão monopolística a humanitarismo, a ela ligada, assim como contra liberdade, igualdade, fraternidade, como postulados totalitários.

4 Contra os programas de um humanismo quiliástico-totalitário, como contra a utopia do homem escatologicamente (endgeschichtlich) ${ }^{8}$ satisfeito e (por isso?) tornado moral, Nietzsche enfatiza o homem efetivo (wirklich), como quando escreve:

"Minha proposição conclusiva é que o homem efetivo apresenta um valor muito mais elevado que o homem desejável" (KSA, v.13, p.56); ou quando, contra "o ideal compreendido como algo em que nada de lesivo, perigoso, questionável, destrutivo deva restar," ele faz valer:

"Nossa compreensão é a inversa: que com cada crescimento do homem, também seu lado oposto tem que crescer, que o mais elevado homem, suposto que tal conceito

\footnotetext{
7 O filósofo americano Richard Rorty qualifica Nietzsche de louco. Ele relativiza, no entanto, seu juizo, de maneira em princípio nietzscheana, ao colocá-lo perspectivamente como condicionado por uma determinada educação e situação histórica. É, contudo, segundo ele, a perspectiva da qual, como americano, ele admite poder convencer todos os homens de sua exatidão. Criticamente a esse respeito: Apel, 1988, p.91-142, em especial p.112 s. Apel cita ai uma passagem da versạ̃o inglesa da elucidativa conferência de Rorty: "O privilégio da democracia sobre a filosofia" (versão alemã igualmente nesse volume, p.273-89). Nas proposiçōes referentes a Nietzsche lê-se, segundo Apel: "Nós, herdeiros da Aufklaerung, pensamos sobre inimigos da democracia liberal como Nietzsche e Loyola como sobre loucos... Eles não são loucos porque teriam quiçá interpretado falsamente a natureza não-histórica do homem. Eles são loucos porque as fronteiras da saúde mental são determinadas por aquilo que podemos tomar a sério. Isso, por sua vez, é determinado por nossa educação, nossa situação histórica"(Idem, p.121). Esta é a consciência de si da linha geral em quase inteira ingenuidade. Nos bastidores, entretanto, espreita também aqui a perspectivística refração nietzscheana, que coloca em questão toda pretensão a universalidade ou absoluto.

8 Tomo a decisão de traduzir o termo "endgeschichtlich" (formado a partir de end, fim ou final, e geschichtlich, histórico) pelo termo escatológico, em parte por não encontrar correspondente em Português, em parte para guardar fidelidade à idéia, visada pela expressão alemã, de fim da história. (N.T.)
} 
seja permitido, seria o homem que mais fortemente exibisse 0 caráter antagonístico do existir (des Daseins)." (KSA, v.12, p.519)

Nietzsche persiste no "terrível texto fundamental homo natura": no homem como ele é por natureza ${ }^{9}$ e intercede a favor de, em primeiro lugar, apreender toda a variedade das aspirações humanas, de acordo com sua tese fundamental sobre a efetividade (Wirklichkeit), segundo a qual esta seria a oposição e o concurso entre si de uma pluralidade de "vontades de poder" heterogêneas e diversamente fortes. Justiça significa, a partir daí, não universalização coordenada com base em pretensa filantropia, porém, de acordo com seu princípio fundamental : "apreensão conceitual e ordenação conjunta de um enorme reino de delicados sentimentos de valor e diferenças de valor, que vivem, crescem, procriam e perecem". ${ }^{10}$

Aqui fala o "outro" Nietzsche, o sensível, que apreende uma efetividade altamente complexa, sobretudo a efetividade humana, que manifestamente não é apenas terrível. Tanto e tão pouco quanto o homem em geral, Nietzsche é terrível. Ele não é nenhum demônio, diabo ou maligno destruidor de razão e humanitarismo, mas um "pobre diabo" (armes Schwein), uma criatura humana sensível, vulnerável e ferida, particularmente pobre porque, como sua cruz, tomou sobre si o pior lado do nosso tempo (Niilismo). A partir desse conhecimento, ele critica o utópico (mais precisamente: quiliástico) humanismo predominante e opõe a ele primeira e ultimamente não a des-humanidade (Inhumanitaet), mas um humanismo realista. Por isso também os programáticos conceitos gerais: humanitarismo e justiça não são, nele, de modo algum negativamente carregados, mas ambivalentes, isto é, positivos ou negativos, conforme se relacionem ao homem efetivo ou ao quiliástico-ideologizado. Nietzsche tem que reconhecer, de acordo com todo seu princípio perspectivístico, que ideologia, isto é, interpretação da efetividade, pode ter conseqüências reais. Segundo ele, todavia, nenhuma ideologia, mesmo que possa também temporariamente ainda predominar muito, pode constranger em seu trilho duradouramente a antagonística pluralidade da efetividade.

5 Deve ser dito com isso que em Nietzsche não haveria utopia em nenhum sentido? Isso não seria adequado à sua filosofia. Ele fala, inclusive, com freqüência suficiente, da necessidade de instituição de novos valores e metas, e desenvolve, pelo menos indicativamente, a figura-meta do "Além-do-homem", à contracorrente da má tendência real em direção ao "último homem" que, no Prefácio a Assim falou Zaratustra é descrito com palavras como: "OO que é amor? O que é criação; o que é saudade; o que é astro?' - assim pergunta o último homem e pisca o olho ... 'Nós inventamos a felicidade' - dizem os últimos homens e piscam o olho."11

9 Nietzche, F. Para além de Bem e Mal, n.230.

10 Idem, n.186.

11 Nietzsche, F. Assim falou Zaratustra, Prefácio, n.5 
Mas, em Nietzsche, a busca da meta para o ulterior desenvolvimento da história humana é diferente, num ponto essencial, de todas as modernas utopias sociais de cunhagem ocidental ou oriental: ela não acredita na melhoria principial da conditio humana, nem do próprio homem, porém vê apenas novas possibilidades, até intensificadas, para a velha tensão entre grandeza e pequenez humana. Condição para 0 nascimento do "Além-do-homem", do qual Nietzsche fala no círculo do "Zaratustra" (mais tarde surgem em seu lugar outros conceitos menos grandiloqüentes), é por isso também o reconhecimento do "eterno retorno do mesmo", cujo sentido capital está decerto em sua antiperfectibilista ênfase na inextirpabilidade da estupidez, mediocridade, crueldade humana e sofrimento por elas causado, assim como de outras formas de sofrimento não causadas por elas.

Somente sobre essa base vale o que Bloch cita como demonstração de seu outro Nietzsche, aquele, pretensamente conforme seu "Princípio Esperança", não meramente "reacionário", mas também "utópico", ou seja:

"Há mil sendas que ainda não foram trilhadas, mil saudades e ocultas ilhas da vida. Sempre ainda inesgotável e não descoberto é o homem e a terra do homem" (Bloch, 1962, p.363).

6 Precisamente o outro Nietzsche, que está por detrás da fachada primeiramente impressionante de suas cativadoras formulações e programas, é um cético sutil e sensivel, um pensador compensatório, que faz valer contra a moderna unilateralidade utópica a antagônica pluralidade da efetividade, sobretudo da humana. Aquele outro Nietzsche que, em contrapartida, Bloch acredita descobrir, o "teólogo que em vão ocupou seu posto na ponte do futuro, cuja história é iluminada pelo deslumbramento de um mundo que ainda não existe"(Idem, p.361), este existe decerto apenas para autores como Bloch. Cegado pela luz rósea da utopia, que no interior do presente brilha a partir do passado da história eurogenética do progresso, ele não enxerga as sombrias nuvens de tempestade da destruição de nossa base natural de vida, que se acumulam no horizonte do futuro. ${ }^{12}$

Esse perigo mortal parece ameaçar o homem mais do exterior, ou seja, com base em suas relações com o mundo ao derredor (Um-welt), com a natureza ambiente exterior. A ameaça está, todavia, estreitamente ligada com as modernas posturas fundamentais do homem para consigo mesmo e para com os outros homens, com seus conceitos antropologicamente limitados de humanitarismo e justiça, com a utopia moral, ou antes, moral-ideológica, baseada em dominação racional, científico-

12 Uma crítica correspondente a Bloch se encontra em Jonas, 1979, em especial p.327 s., p.280 s. um curto capítulo sobre o "Além-do-homem" de Nietzsche. Ele contém a correta interpretação segundo a qual Nietzsche, baseando-se em um fim inteiramente oposto, não utópico, chega igualmente ao ponto de vista de que tudo até então teria sido apenas preparação. O novum seria, segundo Jonas, o reconhecimento do valor do homem efetivo, como este sempre se mostrou na história (cf. Jonas, 1979, "Do já-aí do autêntico homem", p.381 s.). 
técnica da natureza, que Nietzsche já criticara em seu escrito anterior O Nascimento da Tragédia a partir do Espínto da Música, sob o título "socratismo". Tanto mais importante que agora, por meio do colapso contínuo da versão real-socialista da utopia tecnológico-moral, cresceu a chance de ver o homem - quiçá com Nietzsche - de modo mais realista. As formas liberalistas ocidentais da utopia foram, com efeito, colocadas "pós-modernamente" em questão, mas até segunda ordem domina aqui a velha linha geral técnico-quiliástica, e sente-se até fortalecida como única correta pelo colapso de seu até então concorrente.

7 Desde a Revolução Francesa, surgiram sempre de novo as conseqüências terroristas individuais e coletivas da utopia político-moral, tornada crescentemente tecno-quiliástica e com isso tecnocrática, por último no totalitarismo pretensamente humanitário de espécie stalinista. ${ }^{13}$ Os adeptos convictos dessa utopia, que determina a moderna linha geral de visão de mundo (weltanschaulich), se decepcionam sempre de novo com suas conseqüências cruéis - na medida em que sua viseira ideológica lhes libera a vista para tais conseqüências. Desse modo, a convicção deles de que, no fundo, são bem intencionados para com o homem não é abalável em muitos casos, até diante de más experiências. "O contrário do bem é bem intencionado" (gut gemeint), diz em algum lugar o cético Odo Marquard.

Quem, em contrapartida - quiçá com Nietzsche -, se coloca desde o início ceticamente em relação ao homem, não fica decepcionado nem surpreendido. Ele não tinha esperado outra coisa. Desumanidade é humano, dirá ele. No reconhecimento do "terrível texto fundamental homo natura", Nietzsche concorda com Thomas Hobbes. O programa iluminista-progressista de uma crescente realização do humanitarismo pode se reverter em seu contrário, não em último lugar porque não quer admitir essa cética compreensão fundamental do homem.

8 Não subsiste, pois, qualquer diferença real, apenas uma meramente ideológi$\mathrm{ca}$, entre um programa de crescente humanitarismo e um programa como o nazista, que planifica desde o princípio a crueldade intra-humana? Da proposição: "Desumanidade é humano" resulta que sequer se deva tentar praticar e apoiar o humanitarismo, pois a tentativa fracassa de todo modo, pode até causar o contrário daquilo que é querido? Um sistema como o nazista, que considera sub-homem uma parte considerável da humanidade, contra a qual o homem normal ou senhorial pode ser cruel até a destruição, é a conseqüência do ceticismo nietzscheano em relação ao

13 De resto, desembocou também o nazismo, sobretudo sob as condições da total mobilização para fins bélicos, num totalitarismo tecnocrático e foi, nessa medida, especificamente moderno, por detrás de sua fachada ideológica em grande parte romântica, orientada para trás, arcaica: "movimento tecnocrático em vestimenta romântica", diz Sieferle (1984, p.221); analogamente, S. Vietta com referência a R. Dahrendorf e no contexto da crítica heideggeriana da técnica: Vietta, 1989, p.33 s.). 
homem, assim como de sua recusa de todo programa de felicitação da humanidade? A esse respeito, duas considerações:

I. Ceticismo diante do homem e do reconhecimento de seus lados cruéis, agressivos, ávidos de poder e posse não significa qualquer embelezamento desses lados. Eles são e permanecem, como diz Nietzsche, um terrível texto fundamental.

II. Nietzsche não afirma que essas forças impulsivas não tivessem que ser domadas e que elas não o tenham sido efetivamente pelo processo civilizatónio. Ele pergunta também, no entanto, pelo preço dessa domesticação e defende que a domesticação do homem não seja levada longe demais. Seu preço consiste, com efeito, na cruel repressão da crueldade humana (burocracia também pode ser cruel, não apenas terror sangrento), assim como na repressão, atrofia, torção, deslocamento, internalização dos impulsos cruéis.

Além disso, deve-se considerar: domesticação não é supressão. No subsolo fervilham ainda as forças reprimidas, sempre prontas a irromper outra vez:

"Cultura é apenas uma tênue casquinha de maçã sobre um caos incandescente", diz Nietzsche (KSA, v.10, p.362).

9 Ilusionárias e perigosas são, de acordo com isso, doutrinas sociais da felicidade que elevam a programa a supressão, ao invés da domesticação, dos lados cruéis do homem. Elas precisamente - daí áspera recusa, por Nietzsche, do socialismo desembocam em repressão, pois que concedem demasiado pouco livre espaço pluralista para esgotamento das heterogêneas vontades de poder, por exemplo, no econômico.

No que tal repressão é justificada como progressista e filantrópica, pode-se justificar, com ela como base, uma pseudo-aristocracia de vanguarda, modernamente denominada "partido". Assim é que, nos respectivos sistemas, indivíduos e grupos recebem a chance para esgotamento monopolizado de sua vontade de poder. Recente exemplo modelar: o pequeno-burguês romeno Ceausescu, a quem o sistema do socialismo real deu oportunidade de se desenvolver em monstro neofeudalista.

10 O que, pois, opõe Nietzsche a programas repressivos de filantropia? Contra isso, ele defende o reconhecimento de uma efetividade que surge a partir do ímpeto de desdobramento de múltiplas vontades de poder e nele consiste. A tal reconhecimento pertence um conceito de justiça que dá espaço à pluralidade. E o optimum de reconhecimento no âmbito humano é um conceito de filantropia, segundo o qual o homem tem que ser amado apesar de ser ruim como é.

Os homens mal são capazes de um amor dessa espécie: ele é divino e careceria também, segundo Nietzsche, do desvio religioso para poder surgir na história. Manifestamente tendo em vista Jesus Cristo, escreve ele: "Amor ao homem por causa 
de Deus - este foi até agora o mais nobre e remoto sentimento alcançado entre homens".

E ele separa essa filantropia religiosamente mediatizada de um "amor pelo homem sem qualquer santificadora intenção oculta", que seria uma "estupidez e animalidade a mais". ${ }^{14}$

Esse texto parece querer, com efeito, ainda superar a exigência cristã de amor pelo homem fáctico por causa de Deus, por meio de um amor pelo homem como ele poderia ser (Zaratustra fala de amor ao "distante" ao invés de amor ao próximo), sem desvio religioso. Também aqui o ceticismo poderia ser oportuno.

11 Em certas interpretações mais recentes de Nietzsche, sobretudo alemãs ocidentais, "vontade de poder" se torna quase sinônimo de amor e justiça. Com esse moderno soft-Nietzsche, exagera-se a contratendência, em si legítima, ao uso nazifacista desse autor. Há o outro Nietzsche, por detrás das cativadoras fórmulas e sentenças fortes, tendendo à violência. Porém, precisamente ele é um pensador de antagonismos, que também podem certamente ser duros. Há que se compreender que eles se entre-pertencem, se queremos compreender Nietzsche.

A entre-pertença dos antagônicos se segue da hipótese fundamental de Nietzsche acerca de uma pluralidade de vontades de poder que, em caso propício, não provocam nenhum caos, mas procuram criar, cada uma em seu sentido, ordem e hierarquia, e também as criam parcial e temporariamente. Com isso, a vigorosa unificação do múltiplo aparece como algo positivo, ambicionável, tanto se ela ocorre na (possivelmente violenta) imposição de uma perspectiva, como se está ligada com a sábia, também espiritual, visão abrangente (Uebersicht) e reconhecimento da fáctica multiplicidade de perspectivas. Nesse contexto, é claro em Nietzsche (como em Platão - vide seu diálogo Górgias) que, tomado por si mesmo, um ímpeto de desdobramento/vontade de poder, ainda que forte e vital, fracassa quando, ao mesmo tempo, não se interpreta a si e ao campo em redor (as outras vontades de desdobramento com as quais ele tem que se haver), o que significa, no aspecto prático: se não tateia suas chances de realização.

Segundo Mueller-Lauter (1971, p.135 ss.), o ideal nietzscheano do "Além-do-homem" é determinado por essa oposição - não contradição - entre vontade de imposição e sábio pairar acima disso (Darueberstehen). ${ }^{15}$

14 Nietzsche, F. Para além de Bem e Mal, n.60.

15 De acordo com isso, o problema é a união difícil, mas não impossível, de duas coisas: 1. o forte, limitando-se a seu ideal, sua perspectiva; 2. o sábio, acolhendo em si a pluralidade de ideais (Idem, p.138). Formulando de outro modo: trata-se da "síntese do criador, amoroso (Liebender), destruidor" (p.158 - citação de Nietzsche). Segundo Tongeren, (1989, em especial p.182 s.), seria a síntese entre auto-absolutização e auto-relativização, que quer reunir o irreconciliável. E, de fato, essa formulação contém uma contradição insolúvel que, entretanto, não faz justiça à combinação (Miteinander) de tendências caminhando em sentido contrário, suficientemente presentes na efetividade. Não realiza quiçá uma tal sintese todo político que efetua algo a mais longo prazo? Kessler (1988, 
Nietzsche admira inteiramente o papel que desempenhou na história a "fera loura", forte pelo menos de fachada. Porém, em princípio, esse tipo está, para ele, superado, não é modelo para o homem superior do futuro:

"A história humana seria uma coisa completamente estúpida sem o espírito, que nela adveio dos impotentes." 16

A fraqueza do tipo forte de fachada, do aristocrata mais antigo, consiste em que não quer reconhecer a realidade do sofrer. "Isso determina aproximadamente a hierarquia: quão profundamente os homens podem sofrer", ${ }^{17}$ observa Nietzsche em contrapartida.

12 Minha tese é, pois, que a filosofia de Nietzsche não é contraditória em si, antes, porém, diferente do que a princípio se pensa. Quando não se fica preso a seus espetaculares efeitos de fachada, então ela manifesta uma tendência unitária, aspirando a fazer justiça à imensa complexidade da efetividade perpassada por antagonismos. Esse é o lado positivo da coisa. O negativo é - apesar de toda polêmica - a posição frontal não fanática, porém cética, contra toda espécie de fanatismo, de absolutização partidária de uma direção, de uma moral, de uma ideologia de humanidade, e contra o espírito de vingança ligado a esse fanatismo.

Essa camada fundamental suporta a filosofia de Nietzsche desde seu início, e encontra expressão sempre mais clara no curso de seu desenvolvimento. Pontos altos de clareza se encontram na obra póstuma $O$ Anticristo, um dos escritos mais cristãos de todos os tempos. Cristão, com efeito, no sentido em que, contra o cristianismo tal como este se desenvolveu, ele faz valer um cristianismo mais verdadeiro, segundo 0 princípio: "no fundo houve apenas um cristão, e este morreu na cruz". ${ }^{18}$ Logo em seguida à sua morte, prevaleceu de novo, como diz Nietzsche, "o sentimento mais não-evangélico" ("não-evangélico" no sentido de: dirigido contra a mensagem de Jesus), ou seja, o desejo de vingança carregado de ressentimento, primeiramente dirigido contra o judaísmo oficial, que promoveu a execução de Jesus. Esse enfático antifarisaismo faz de Jesus aquilo precisamente que ele não quis ser: "um fariseu e um teólogo", 19 isto é, um homem de partido com convicções dogmaticamente fixadas.

p.322) reconheceu em um dos políticos mais poderosos em efeitos, ou seja, em Bismarck, precisamente esse pressuposto do êxito. A esse respeito, escreve ele: "... eu o vi também em consequiência dessa relação humana em uma luz essencialmente outra que a maioria de meus jovens contemporâneos: ou seja, não como o gigantesco e semi-urbano cavaleiro encouraçado..., como o apresentam os monumentos e os editorialistas, porém como um velho diplomata muito cuidadoso, vigilante, com uma voz aguda, quase feminina, que, infinitamente sensivel em cada momento, tateava as fronteiras de seu poder, como uma beata o seu rosário e, precisamente ao contrário dos fedelhos diplomatas que esmurram a mesa, se esforçava permanentemente para se impor sem o emprego de violência; sobretudo, porém, para não ultrapassar os limites do seu poder efetivo".

16 Para a Genealogia da moral, primeira dissertação; n.7; cf. KSA, v.13, p.323.

17 Nietzche, F. Para além de Bem e Mal, n.270.

18 Nietzsche, F. O Anticristo, n.39.

19 Idem, n.40. 
No contexto dessa interpretação de Cristo, Nietzsche retoma uma questão de seu escrito anterior Humano, demasiado Humano: "se as convicções não são inimigos mais perigosos da verdade do que as mentiras", e a aguça na questão: "existe, em absoluto, uma oposição entre mentira e convicção?". ${ }^{20}$ Ele faz então outras extensões ao complexo mentira-conviç̧ão-partidarismo, que eu gostaria de citar neste contexto. Quem as lê e toma conhecimento de seu central valor posicional na filosofia de Nietzsche, a esse pode parecer claro que todas as unilateralidades partidárias, sobretudo políticas, cobranças ou condenações de Nietzsche são por ele exortadas a, em primeiro lugar, provar-se a si mesmas: "Eu denomino mentira o não querer ver algo que se vê, não querer ver algo assim como se o vê ... A mentira mais costumeira é aquela com a qual mentimos para nós mesmos; o mentir para outrem é relativamente exceção. - Ora, esse não querer ver é ... quase a primeira condição para todos que são partido em algum sentido: o homem de partido se torna necessariamente mentiroso". ${ }^{21}$

E precisamente também antipartidarismo fanático, quiçá ligado à afirmação que a própria posição estaria para além de toda ideologia ou interpretação perspectiva é, segundo ele, opacamente ideológico e partidário. É impossível não ter nenhuma conviç̧ão. Mas além de seu conteúdo, importa do mesmo modo como se a tem. A esse respeito, Gomez Dávila (1987, p.59), um autor hoje vivo, de espírito nietzscheano, diz: "Só o estúpido nunca se sente como partidário de seu opositor."

13 O outro, o Nietzsche de início oculto é, pois, aquele para quem o tema amor e justiça, num sentido que abrange homem e coisas, é central. Ele próprio reflete este traço fundamental de sua filosofia só bem tarde, no projeto de um prefácio do ano 1885. Lá ele apresenta justiça como algo que teria faltado em suas reflexões, que só "tardiamente" se teria tornado consciente para ele (depois de seus vinte anos: bastante cedo, portanto):

Que eu me desse conta do que propriamente me faltasse, ou seja, a justiça, ocorreu tarde - eu já passara dos vinte anos - "O que é justiça? É ela possível? E se ela não devesse ser possível, como se haveria de suportar a vida?" - desse modo eu me questionava sem cessar. Assustava-me profundamente encontrar por toda parte onde escavava em mim mesmo apenas paixões, apenas perspectivas de um ângulo (Winkel-Perspektiven), apenas a inescrupulosidade daquilo a que já faltam as pré-condições da justiça: onde estava a circunspecção? - ou seja, a circunspecção a partir da compreensão vasta? (KSA, v.11, p.663 ss.)

Com efeito, o perspectivismo de Nietzsche abre, em geral, o espaço de jogo, ou livre espaço entre dois pólos: 1. as múltiplas perspectivas efetivas e possíveis e 2. a procura de perspectivas abrangentes. Positivamente, estas existem, segundo ele, e

20 Idem, n.55.

21 Idem, Ibid. 
são até mesmo valoradas como hierarquicamente superiores, ${ }^{22}$ por outro lado, falta a uma (platônica?) metaperspectiva, a posição de absoluta, dogmática verdade. Contra toda unificação nesse sentido, mas também contra toda precipitada coordenação por meio de sobreperspectivas relativas, o perspectivismo angular (Winkel-Perspektivismus) de Nietzsche, assim como sua sensível apreensão da realidade rica em nuanças ${ }^{23}$ fazem valer a antagônica multiplicidade.

Num fragmento póstumo do ano 1880, lê-se:

Minha tarefa: sublimar de tal modo todos os impulsos que a percepção daquilo que é desconhecido (das Fremde) vá muito longe e esteja, todavia, associada a prazer: o impulso de honestidade para comigo, de justiça para com as coisas, tão forte que suas alegrias preponderem sobre o valor das outras espécies de prazer e, se necessário, estas sejam total ou parcialmente sacrificadas a ele. Na verdade, não existe contemplação desinteressada, isso seria o tédio completo. Basta, porém, a delicadíssima emoção. (KSA, v.9, p.211)

Esse Nietzsche da delicadíssima emoção, da colocação entre parênteses da própria perspectiva de um ângulo, da justiça, assim tornada possível, para com a multiplicidade da realidade, não se deve negligenciá-lo em proveito do Nietzsche que em primeiro lugar salta aos olhos, o das fortes palavras e programas, entre eles programas de violência política e aparentemente apenas caótica desrepressão. Nesse sentido de justiça, há que se fazer justiça também para com a complexidade de Nietzsche. A interpretação de Nietzsche só chegou a isso por meio de tentativa e erro, ou seja, também por meio de experiências ruins com tentativas de emprego político de um Nietzsche unilateralmente concebido. ${ }^{24}$

Também uma tal interpretação depurada não pode tornar Nietzsche inequívoco. Quando se lê com rigor suficiente, nele se descobrirá sempre uma dupla diretiva: uma vez, a indicação da pluralidade de perspectivas, como perigo correspondente de nela se perder ("Infinitude! É belo sucumbir nesse mar"25); em seguida, a exortação à vigorosa, hierárquica unificação do múltiplo, com o correspondente perigo da violenta unilateralidade e injustiça. Nietzsche denomina justiça a difícil união de ambos. $\mathrm{O}$

22 "Tu deverias aprender a compreender a necessária injustiça em todo pró e contra, a injustiça como inseparável da vida, a vida mesma como condicionada pelo perspectivo e sua injustiça. Sobretudo deverias ver com os olhos onde a injustiça é sempre maior: lá, decerto, onde a vida se desenvolve minimamente, da maneira mais estreita, carente, incipiente, e, no entanto, não pode deixar de se tomar como fim e medida das coisas, e, por amor de sua conservação, continuamente despedaçar e colocar em questão clandestina e mesquinhamente o mais elevado, o maior, o mais rico - deverias ver com os olhos o problema da hierarquia e como poder e direito e envergadura da perspectiva crescem conjuntamente em altura." (Nietzsche, KSA, v. 2, prefácio, n.6)

23 Nietzsche, F. Para além de Bem e Mal, n.31

24 F. Kaulbach coloca sobretudo o tema da justiça no proscênio de sua interpretação de Nietzsche; cf: A virtude da justiça e o conhecer filosófico. In: Nietzsche-Kontrovers I. Wuerzburg, 1951, p.59-76; também: A idéia de Nietzsche de uma Filosofia Experimental. Colônia, Graz, 1980. Apreciando e criticando esse livro, cf. R. Maurer: Nietzsche harmônico? In: Nietzsche-Studien, v.12, p.497-506, 1983.

25 KSA. 9, p.290. Cf. R. Maurer. Nietzsche e o experimental In: Para a atualidade de Nietzsche. Simon, Wuerzburg. 1984, v.I, p.7-28. 
êxito dela é e permanece inseguro, sobretudo na época do Niilismo, isto é, da dissolução das antigas representações de caminhos viáveis da justiça.

\section{Referências bibliográficas}

1 APEL, O. De volta à normalidade? Ou: poderíamos ter aprendido algo especial com a catástrofe nacional? In: Destruição da consciência moral: chance ou periclitação? Frankfurt a. M.: Forum fuer Philosophie Bad Homburg, 1988.

2 BLOCH, E. Herança deste tempo. Ed. ampl. Frankfurt a. M., 1962. (O impulso Nietzche). 3 . O princípio esperança. Frankfurt a. M.: s.n., 1959.

4 GOMEZ DÁVILA, N. Solidões. Viena: s.n., 1987.

5 JONAS, H. O princípio responsabilidade. Ensaio de uma ética para a civilização tecnológica. Frankfurt a. M.: s.n., 1979.

6 KESSLER, H. G. Perfis e tempos. Frankfurt a. M.: s.n., 1988.

7 MUELLER-LAUTER, W. Nietzsche. Sua filosofia dos contránios e os contrários de sua filosofia. Berlim: s.n., 1971.

8 NIETZSCHE, F. Obras completas. Ed. crítica de estudos (Kritische Studienausgabe). Munique: G. Golli, M. Montinari, 1980.

9 SIEFERLE, H. P. Inimigos do progresso? Oposição contra técnica e indústria do nacional-socialismo até a atualidade. Munique: s.n., 1984.

10 TONGEREN, P. van. A moral da crítica nietzcheana da moral. Estudos sobre Para além de Bem e Mal. Bonn: s.n., 1989.

11 VIETTA, S. A crítica de Heidegger ao nacional-socialismo e à técnica. Tubinga: s.n., 1989. 